\title{
Near-surface Seismic Velocity Model Building from First Arrival Travel-times - A Case Study from an Onshore, Niger Delta Field
}

\author{
Opara, C., Adizua, O. F. , Ebeniro, J. O. \\ Applied Geophysics Research Group, Department of Physics, University of Port-Harcourt, Nigeria
}

Copyright $(2018$ by authors, all rights reserved. Authors agree that this article remains permanently open access under the terms of the Creative Commons Attribution License 4.0 International License

\begin{abstract}
Seismic refraction was used to image the near-surface, using a 3D seismic data acquired from an onshore Niger Delta field. The objective of the study was to build a near-surface model of the earth in terms of sub-weathering layer thicknesses and seismic wave velocities and highlight the near-surface seismic wave velocity variation in the region. A velocity-depth model consisting of the weathering layer and three consolidated (sub-weathering) layers was first estimated. The first-breaks were picked and used as input for this study. The models were generally consistent in terms of their large-scale features, demonstrating the robustness of refraction data inversion in general. Results support confidence in the reliability and robustness of the refraction inversion method. The method of analysis and resolution for 3-layer models adopted in this study may be used in resolving such cases observed during processing of seismic reflection data from the Niger-Delta Basin.
\end{abstract}

Keywords Seismic Refraction, Near-surface Earth Model, Velocity Depth Model, First Breaks, Refraction Data Inversion, Niger Delta Basin

\section{Introduction}

The ultimate goal in reflection seismic data processing is to obtain an accurate image of the subsurface, which is critical for interpretation during exploration for hydrocarbons and other geological targets. The near surface is considered as the shallow part of the subsurface whose properties distort or degrade the response from deeper targets. It is also the part of the subsurface in which the majority of seismic coherent noise propagates. Characterization of shallow subsurface layers is of particular interest for exploration seismology.

A near-surface velocity model is crucial to seismic data processing; including static corrections and migration. The mechanics shows that near-surface velocities as well as that of the weathered layer are a prerequisite for these processes.
Refraction methods represent techniques that are based on constructing a realistic model of the shallow subsurface by inverting the refracted (first break) arrivals [1]. This model should incorporate the complete topography, as well as the variations in the structure of the weathered zone. For refraction arrivals recorded as part of a reflection survey, the probability of success of the refraction methods heavily depends on some factors such as the quality of the first arrival (refracted waves) associated with the refractor, the complexity of subsurface geology and offset distance. Redundancy provided by the seismic reflection survey is also a positive factor [2].

Our primary objective for this study is to build a near-surface seismic model of the earth in terms of sub-weathering layer thicknesses and seismic wave velocities from first arrival travel times.

\subsection{Location and Geology of the Study Area}

The present field denoted by the orange block in Figure 1 is underlain by the sediments of the Niger Delta basin. It is a few kilometers south-west of Port-Harcourt, Rivers State, Nigeria. The stratigraphic sequence of the Niger Delta comprises three broad lithostratigraphic units namely,

(1) A continental shallow massive sand sequence - the Benin Formation

(2) A coastal marine sequence of alternating sands and shales - the Agbada Formation and

(3) A basal marine shale unit- the Akata Formation.

The sand percentage in the Akata formation is generally less than 30\%. The Agbada Formation consists of alternating sand and shales representing sediments of the transitional environment. The sand percentage within the Agbada Formation varies from 30 to $70 \%$. The Benin Formation is characterized by high sand percentage $(70-100 \%)$ and forms the top layer of the Niger Delta depositional sequence [3]. The massive sands were deposited in continental environment. The sediments of the Niger Delta span a period of 54.6 million years [4]. 


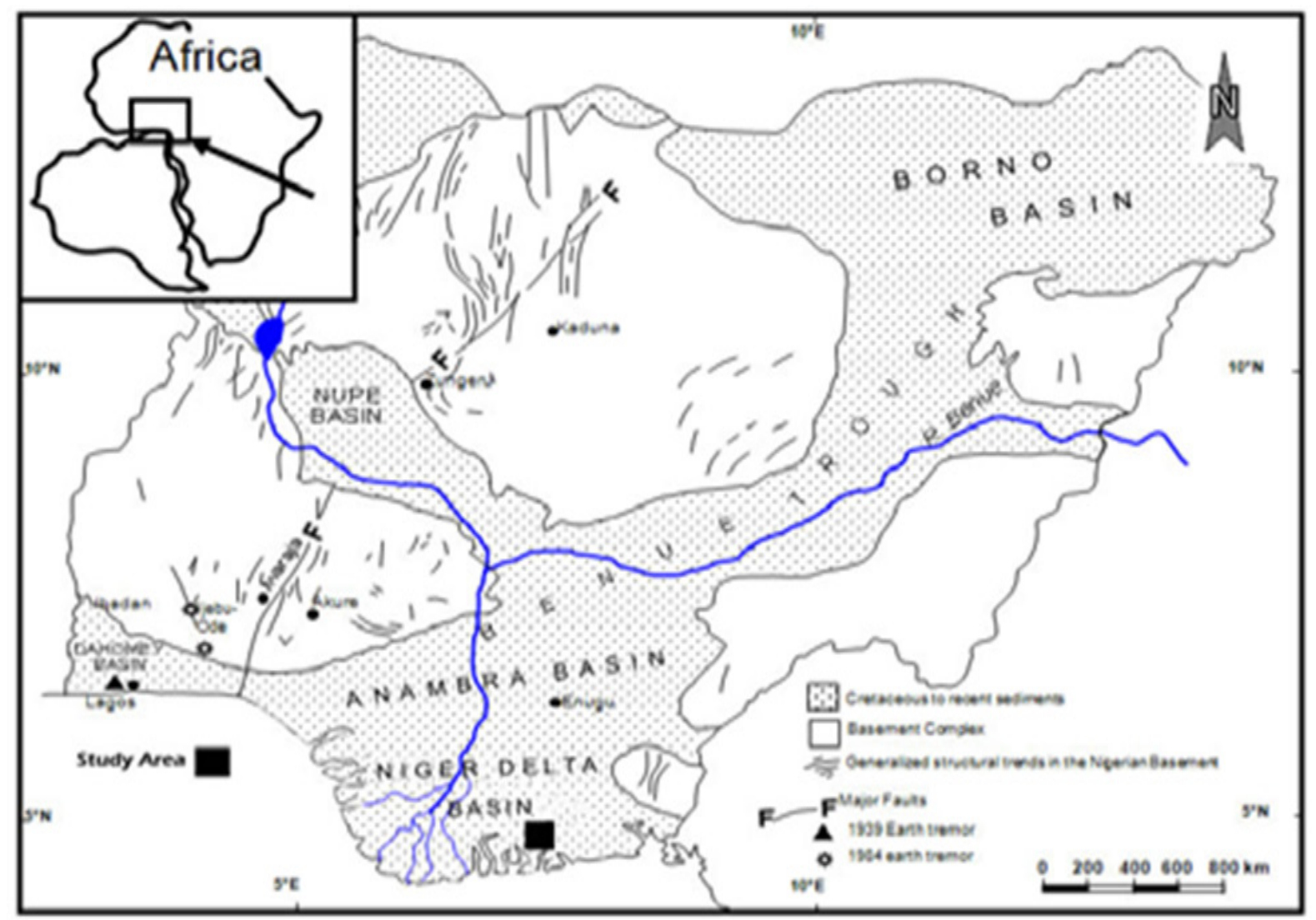

Figure 1. Generalized geologic map of Nigeria showing the study area; Odeyemi et al., 1999 [5].

\section{Materials, Method and Data Processing}

A 3D seismic survey was acquired over the field which is a challenging area for onshore seismic exploration because of rapid topographic variations. The field is in a swampy terrain with complex surface conditions which unavoidably introduced serious issues (data gaps) for data acquisition, static corrections and the data signal-to-noise ratio. The subsurface geology and velocity distribution is also complex. Variations in topography, thickness and velocity of the weathering layers can result in variable travel times of the seismic arrivals. It is pertinent to state that the up-hole coverage for this field is sparse and the sampling is not enough to describe the complex geology. Incorrect long-wavelength structure can be introduced by the use and interpolation of sparse up-hole sampling and leads to derivation of sub-optimal statics. For these reasons, it is better to use the model derived from refraction inversion for statics as was implemented in the study.

The data used for the present study is a $3 \mathrm{D}$ prestack onshore seismic data with the accompanying geometry/SPS files. This data was acquired with dynamites as source. Impulsive sources such as this yield fairly clear signals. The data had a high signal-to-noise ratio with several receiver and source lines. The receiver lines are trending in the North-South direction. The cross-lines or source lines are trending in the East-West direction. First arrival travel-times from the seismic data were extracted and used as input for the study.

The first approach was to bin the data using the geometry or SPS files. Each Bin Grid had a dimension of $24.9 \times 24.9$ meters, before picking the Linear-moveout (LMO) velocity which was used to identify geometry errors and check for departures from the location of the receivers or shot point. Linear-moveout analysis was subsequently done on the full data spread by running appropriate Vista flow commands. 


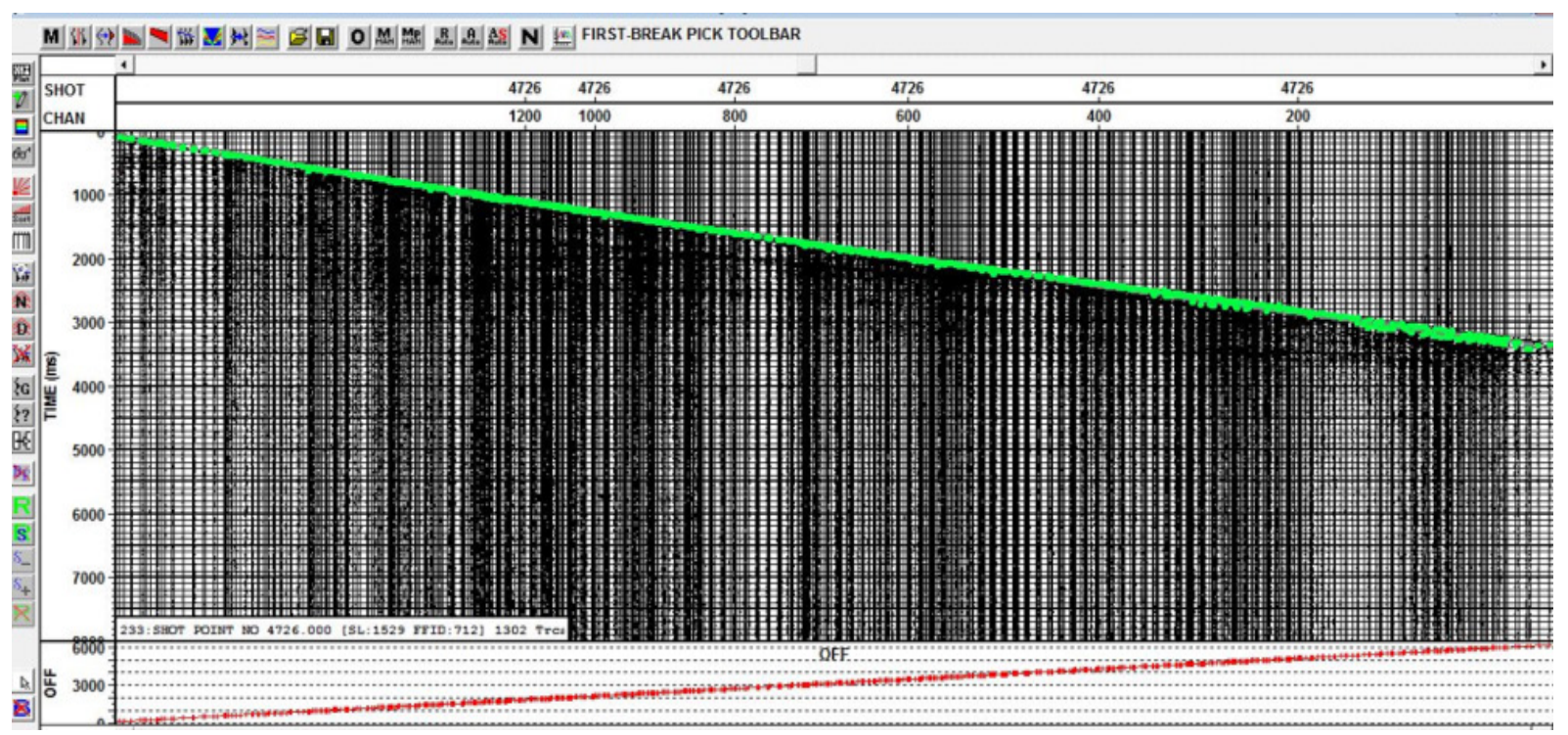

Figure 2. First break picks overlaid on Seismic data

Next, the first break-picking was first done manually for a few shots, and then automated (Figure 2) using the automatic picker with the LMO function to pick the entire dataset and correct the results interactively by visual inspection and performing QC analysis on them. There were 483 first-break picks.

\subsection{Modeling Approach}

Refraction technique utilizes the travel-times of critically refracted seismic energy to compute the depth and velocity structure of near-surface layers [6]. This method can indirectly estimate intercept time and bedrock velocity using the first-arrival times and uses this to estimate a velocity and depth model at all location within the survey area. The velocities of the 3 layers are picked along the first breaks within the offset window [7]. First-arrival times from the far offsets are included to make sure the model inversion is stable and accurate with more information included. It uses the multiplicity of first-break data available in multi-fold reflection surveys to determine the number of refractors present and to calculate statistically, robust refractor velocities. This approach resolves high vertical-velocity contrasts and also provides high resolution solutions in simple near-surface situations. The procedure equally entails picking a control point (either source or receiver point) (Figure 3) across the survey area and checking the corresponding picks for any scattering and deviations from the gather. Having found the results desirable, we proceeded to generate the velocity and depth profiles for the various layers. 


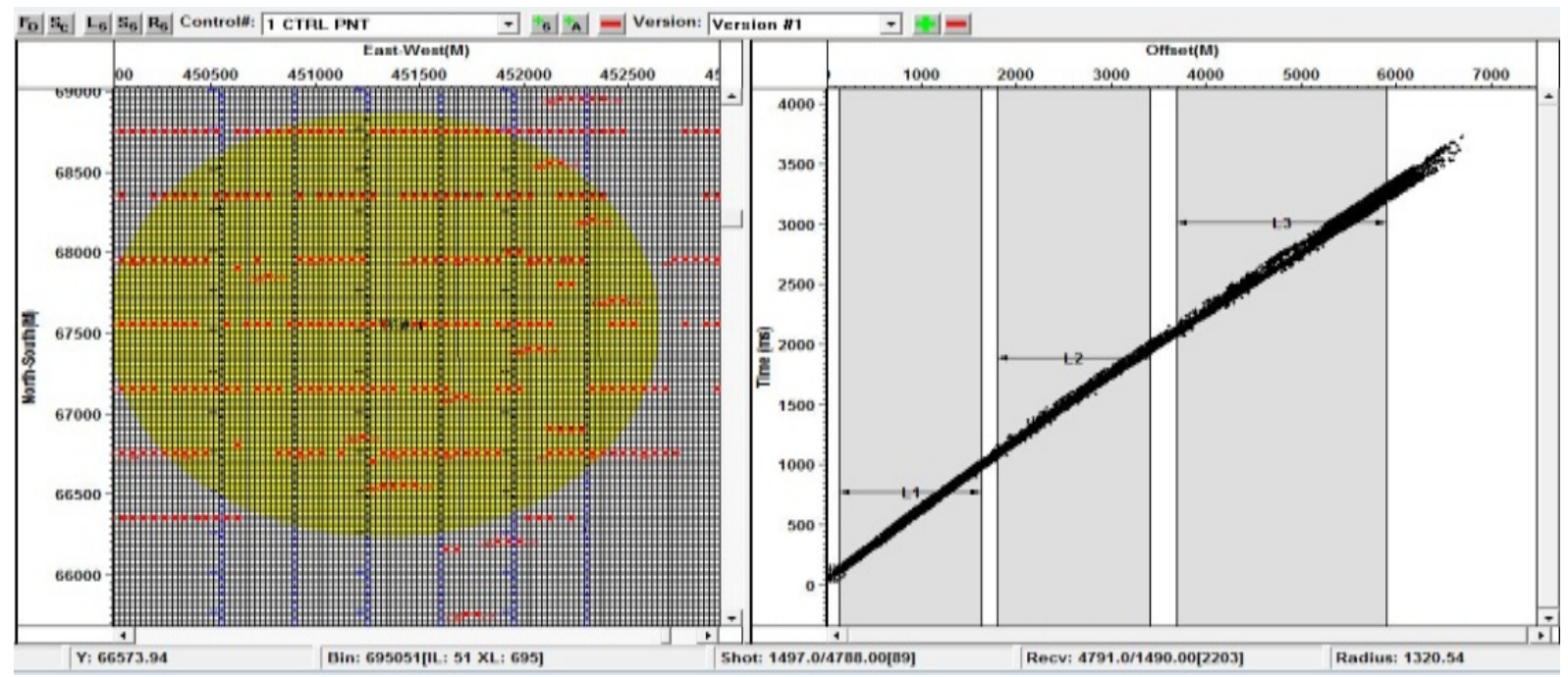

Figure 3. Control point in geometry window (left) and corresponding first-break pickswith 3-Layers in offset window (right).

Control points in the geometry window are typically a collection of many shots (10-20) or groups of receivers. The control points attempt to get a reasonably accurate long wavelength picture of the near surface layer changes. An increment in the number of shots inside the circle does have a smoothing effect on the solution. A total of 1253 control points were automatically created.

\section{Data Interpretation and Discussions}

The velocity-depth models derived from the 3D seismic dataset are presented in Figures 4- 7. The velocity profiles aid in understanding lateral velocity variations within the specified layers, while the depth models aid in determining the thickness of the various layers. The results show a near-surface model, consisting of the velocity and thicknesses of the weathered layer and three subsequent layers. The weathered layer (Figure 4) overlying the first consolidated layer, consists of low velocity $(450 \mathrm{~m} / \mathrm{s})$ unconsolidated sediments, with a thickness varying from $3 \mathrm{~m}$ to about $15.26 \mathrm{~m}$, and has an average thickness of $10.46 \mathrm{~m}$.

From the first consolidated layer (Figure 5A \& 5B), the depth ranges from $11.79 \mathrm{~m}$ to about $108 \mathrm{~m}$ in the cross-line direction, while depth ranges from $8 \mathrm{~m}$ to about $130 \mathrm{~m}$ in the in-line direction. The average velocity is about $1700 \mathrm{~m} / \mathrm{s}$ and an average thickness of about $100 \mathrm{~m}$. From the first consolidated layer also (Figure 8.0A), seismic velocities within this layer appear to decrease in the East-West direction where lower velocities of $1200 \mathrm{~m} / \mathrm{s}$ to $1590 \mathrm{~m} / \mathrm{s}$ are observed at the edges.

In the second consolidated layer (Figure 6A \& 6B), the depth ranges from $50.02 \mathrm{~m}$ to about $326.62 \mathrm{~m}$ in the X-line direction and $65 \mathrm{~m}$ to about in the In-line direction. It has an average thickness of $210 \mathrm{~m}$ and an average velocity of $1760 \mathrm{~m} / \mathrm{s}$. Layer 2 is the thickest amongst all the layers. The distribution of seismic velocities for this layer (Figure 8B) increases in the east-west direction with varying seismic velocities from $1750 \mathrm{~m} / \mathrm{s}$ to $1780 \mathrm{~m} / \mathrm{s}$ and higher seismic velocities of $1774 \mathrm{~m} / \mathrm{s}$ to $1790 \mathrm{~m} / \mathrm{s}$ observed at the edges.

In the third consolidated layer (Figure 7A \& 7B), the depth ranges from about $270.40 \mathrm{~m}$ to about $484.03 \mathrm{~m}$ in the crossline (X-line) direction and $320 \mathrm{~m}$ to about $481.78 \mathrm{~m}$ in the In-line direction. The average thickness in this layer is about $156 \mathrm{~m}$ with an average velocity of about $1930 \mathrm{~m} / \mathrm{s}$. From the third consolidated layer (Figure 8C), an average seismic velocity distribution of about $1936 \mathrm{~m} / \mathrm{s}$ was observed within the layer with concentrated pockets of high seismic velocities of $1956 \mathrm{~m} / \mathrm{s}$ also observed. Low seismic velocities of about $1910 \mathrm{~m} / \mathrm{s}$ were also observed in the north-east direction.

Generally, seismic velocities within the consolidated layers were noticed to increase with progressive depth. This velocity model essentially shows a velocity structure that varies gradually within the various layers and incised valley that is seismically identifiable (Figure 8C) and may even demonstrate a type of minor artesian aquifer for the shallow substratal horizons underlying the study area. The seismic velocity trends obtained are typical of sediments deposited in the Niger-delta. 


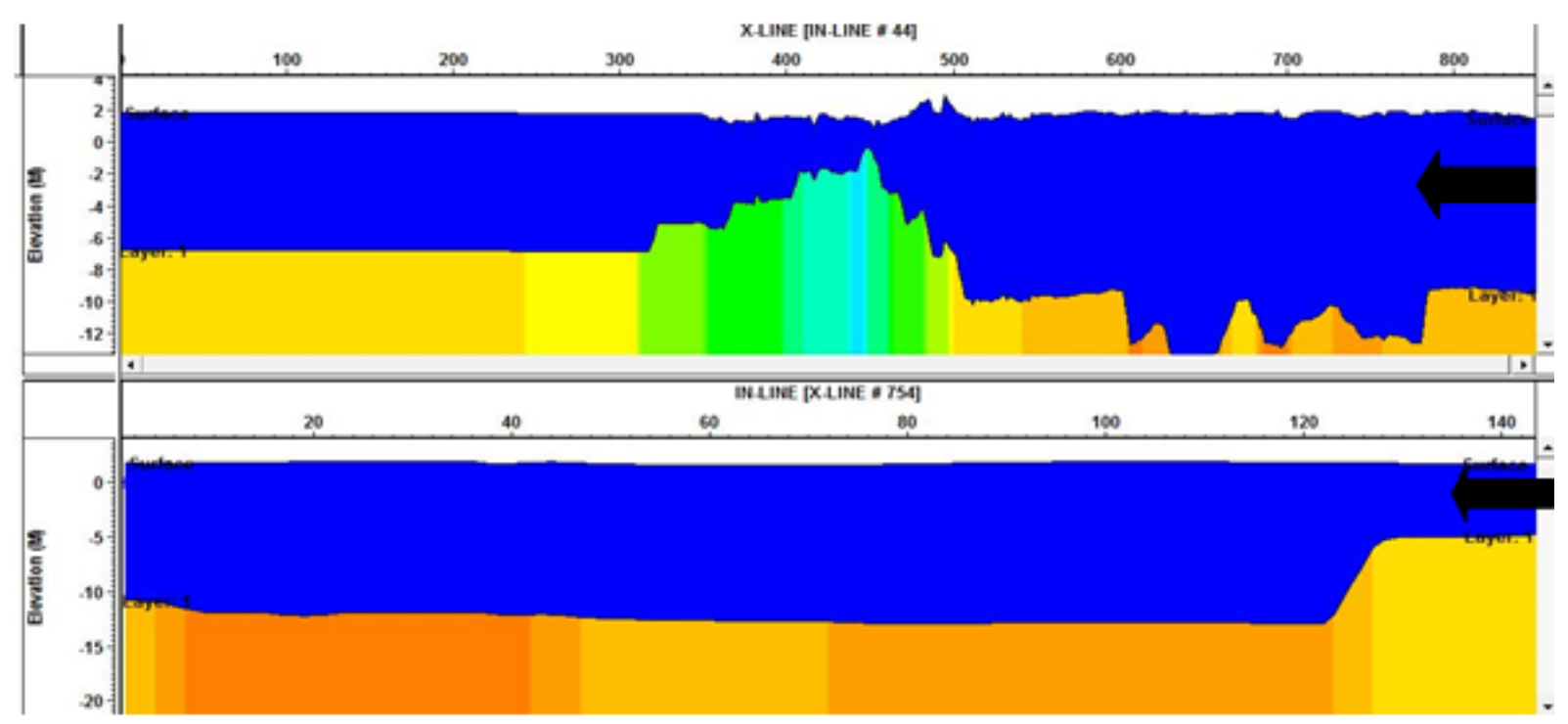

Figure 4. Distribution of weathering velocity and thickness across the study area (bluecolor).

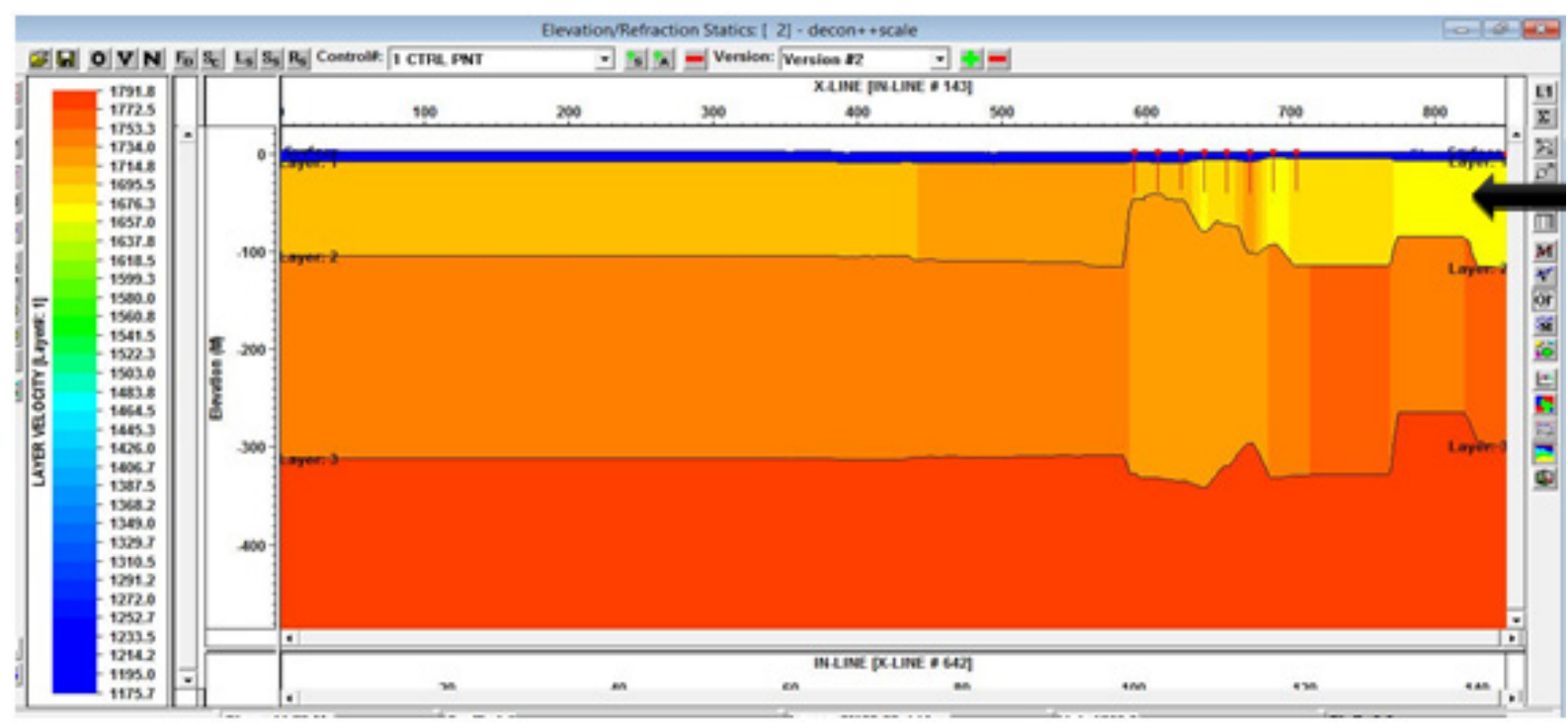

Figure 5A. Cross-Line structural profile and thickness distribution for first layer.

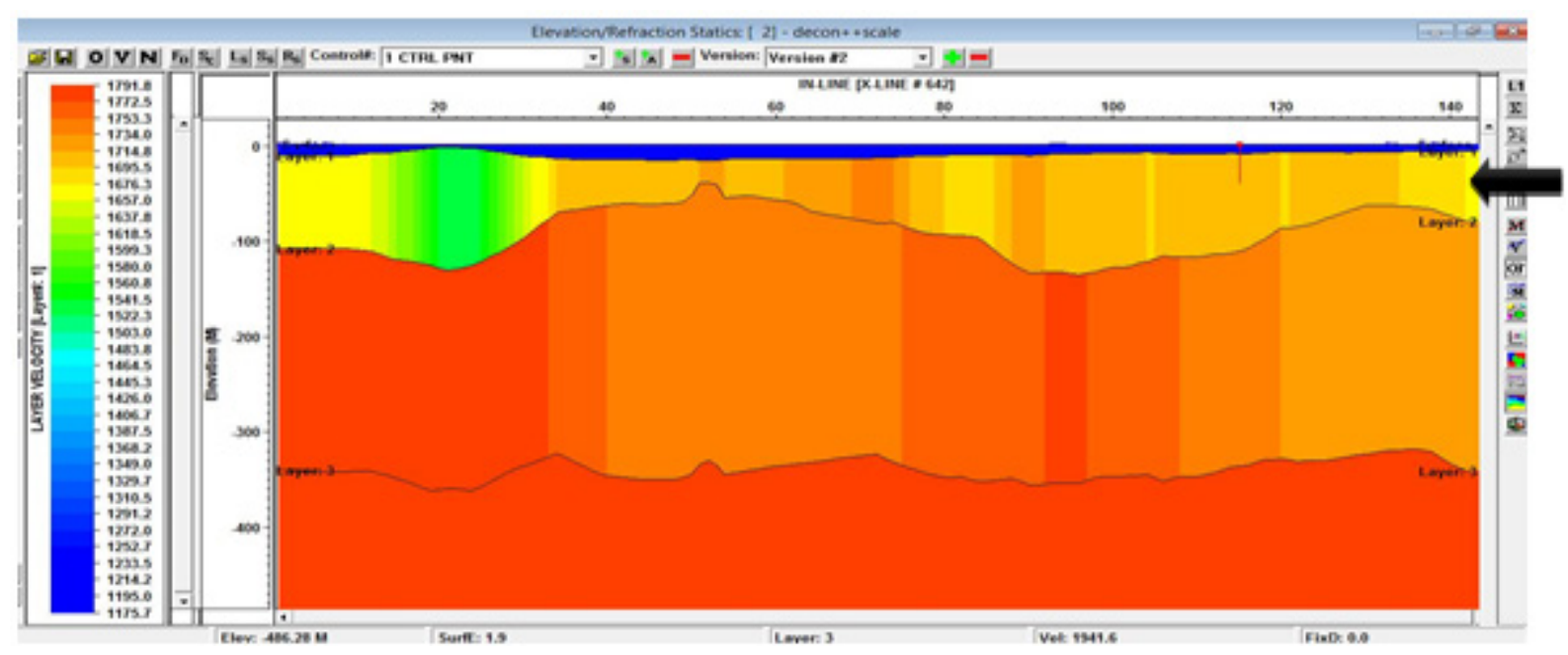

Figure 5B. In-line structural profile and thickness distribution for first Layer. 


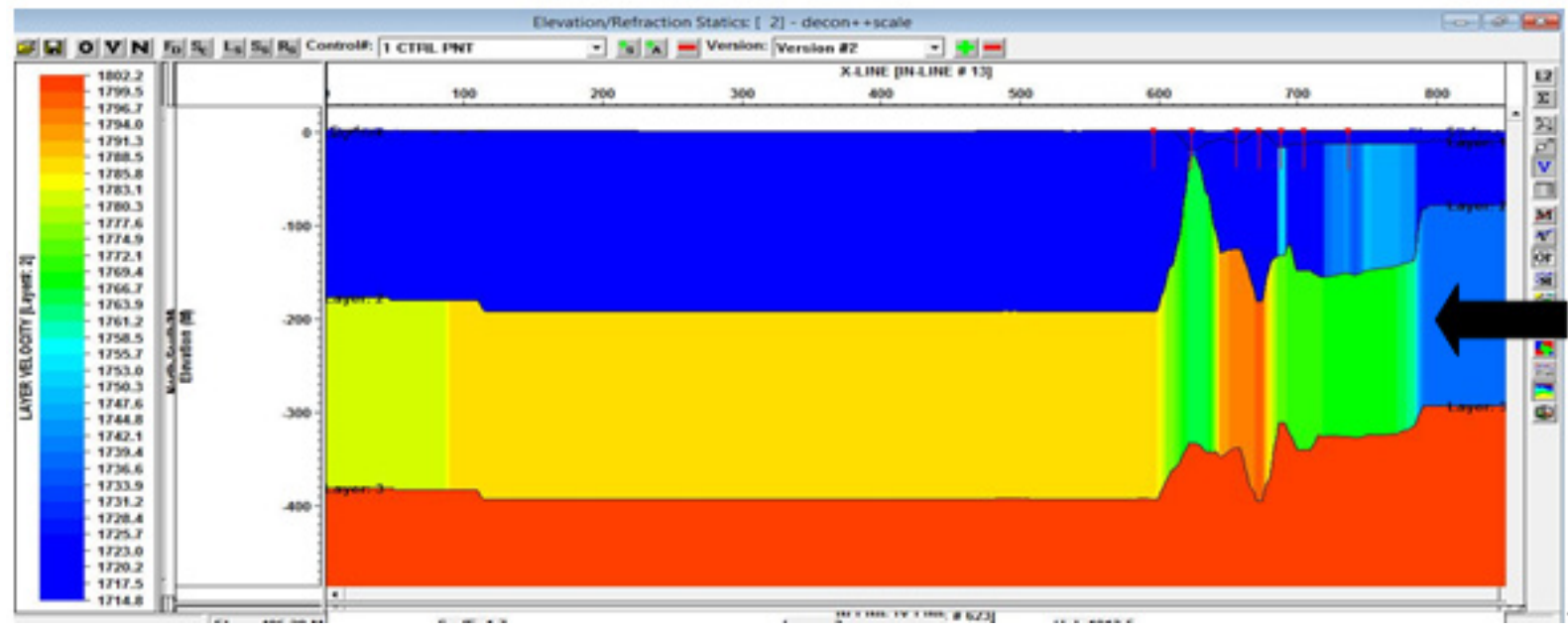

Figure 6A. Cross-Line structural profile and thickness distribution for the second layer.

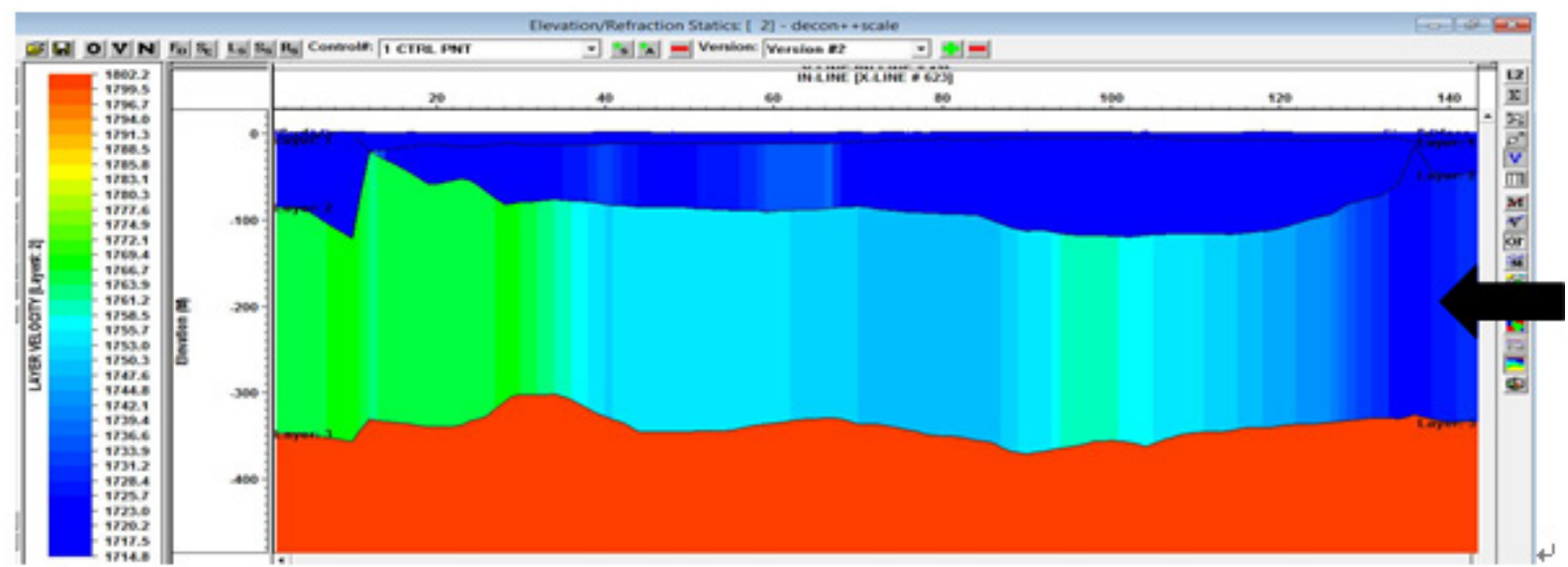

Figure 6B. In-line structural profile and thickness distribution for the second layer.

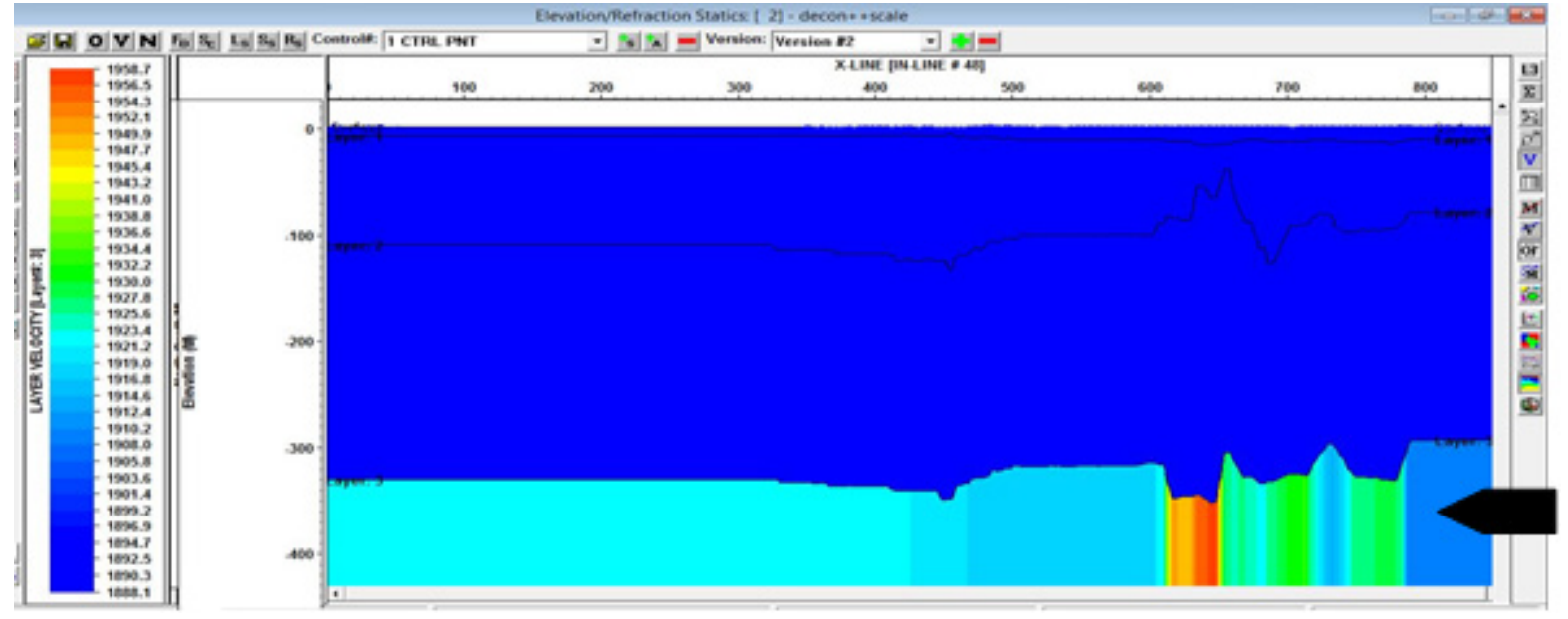

Figure 7A. Cross-Line structural profile and thickness distribution for third layer 


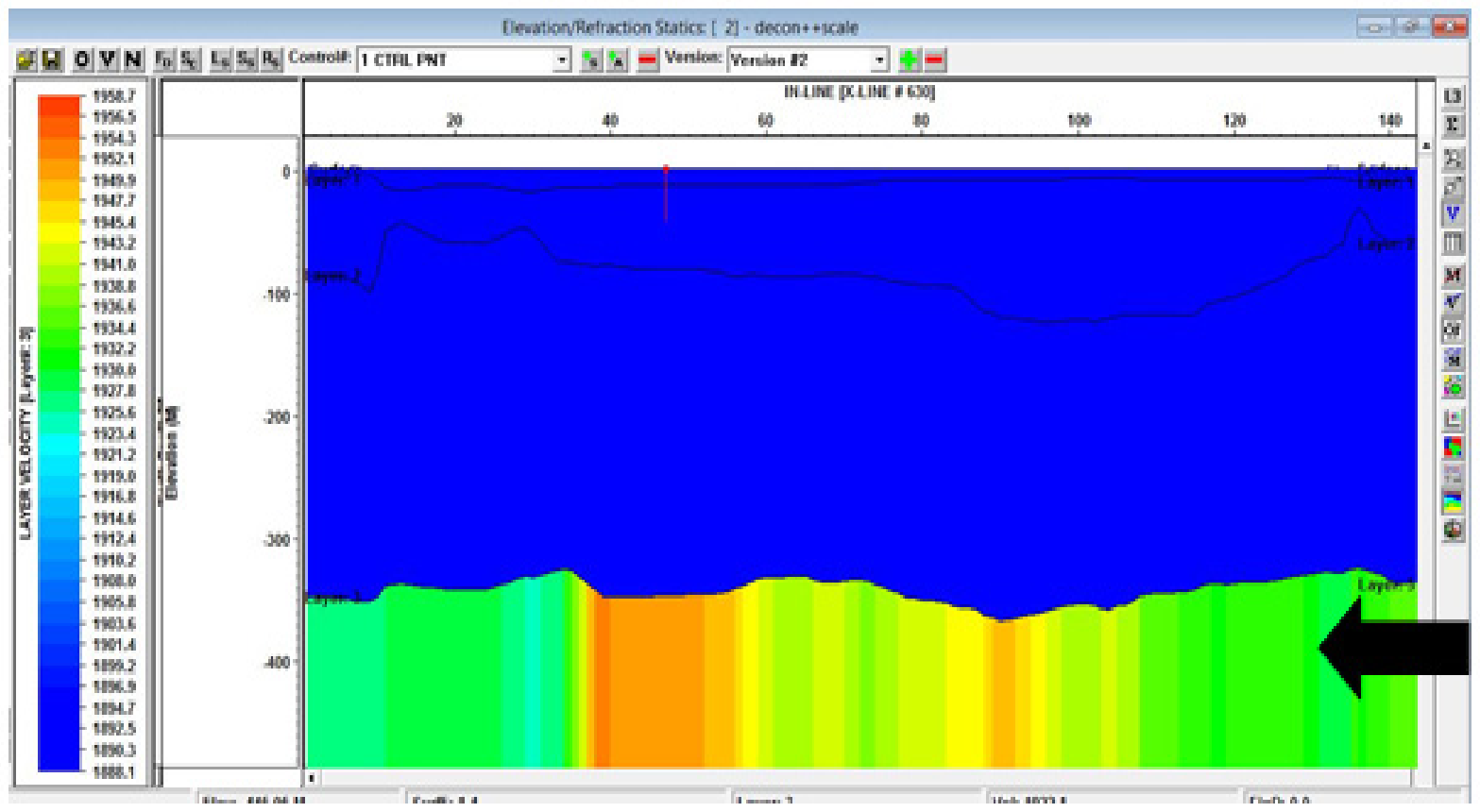

Figure 7B. In-line structural profile and thickness distribution for third layer.
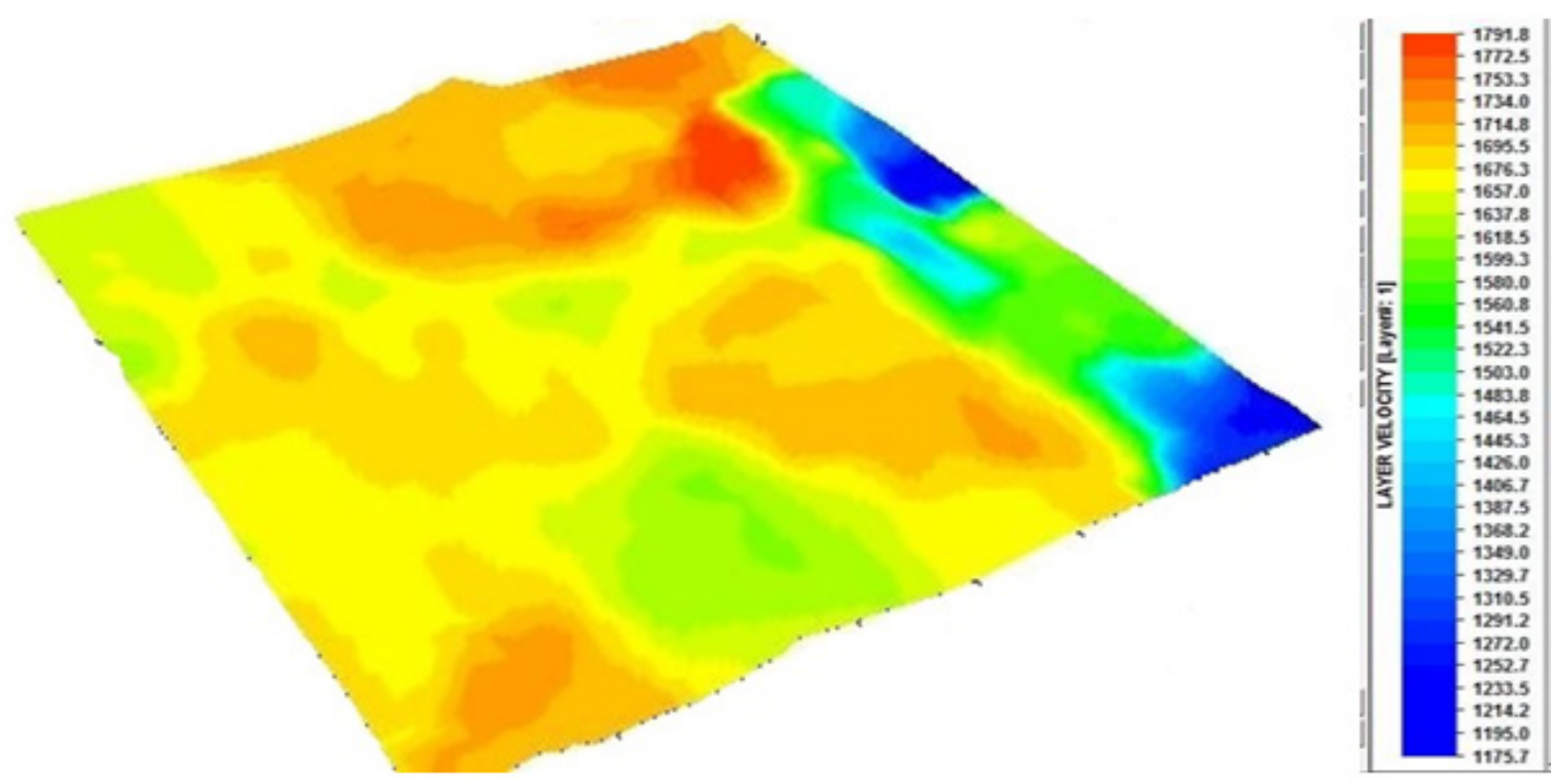

Figure 8A. Distribution of lateral velocity variation across the first consolidated layer. 

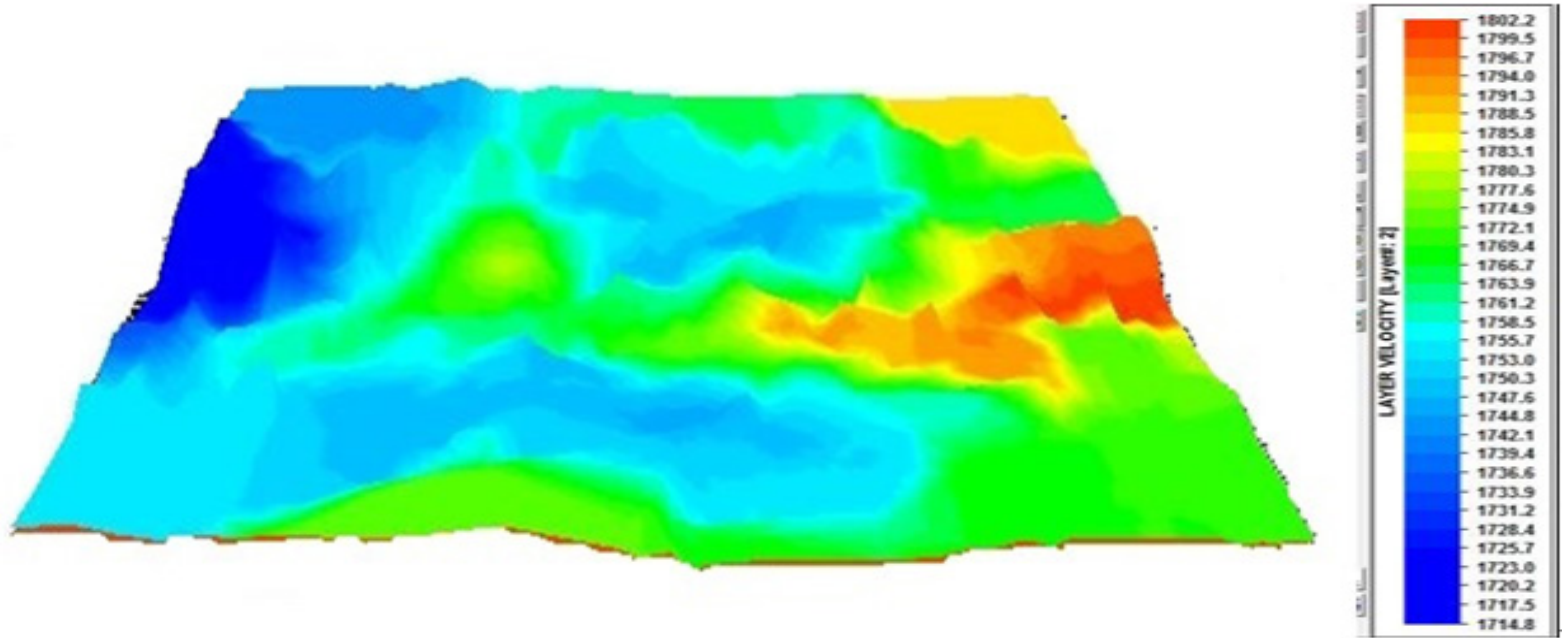

Figure 8B. Distribution of lateral velocity variation across the second consolidated layer.

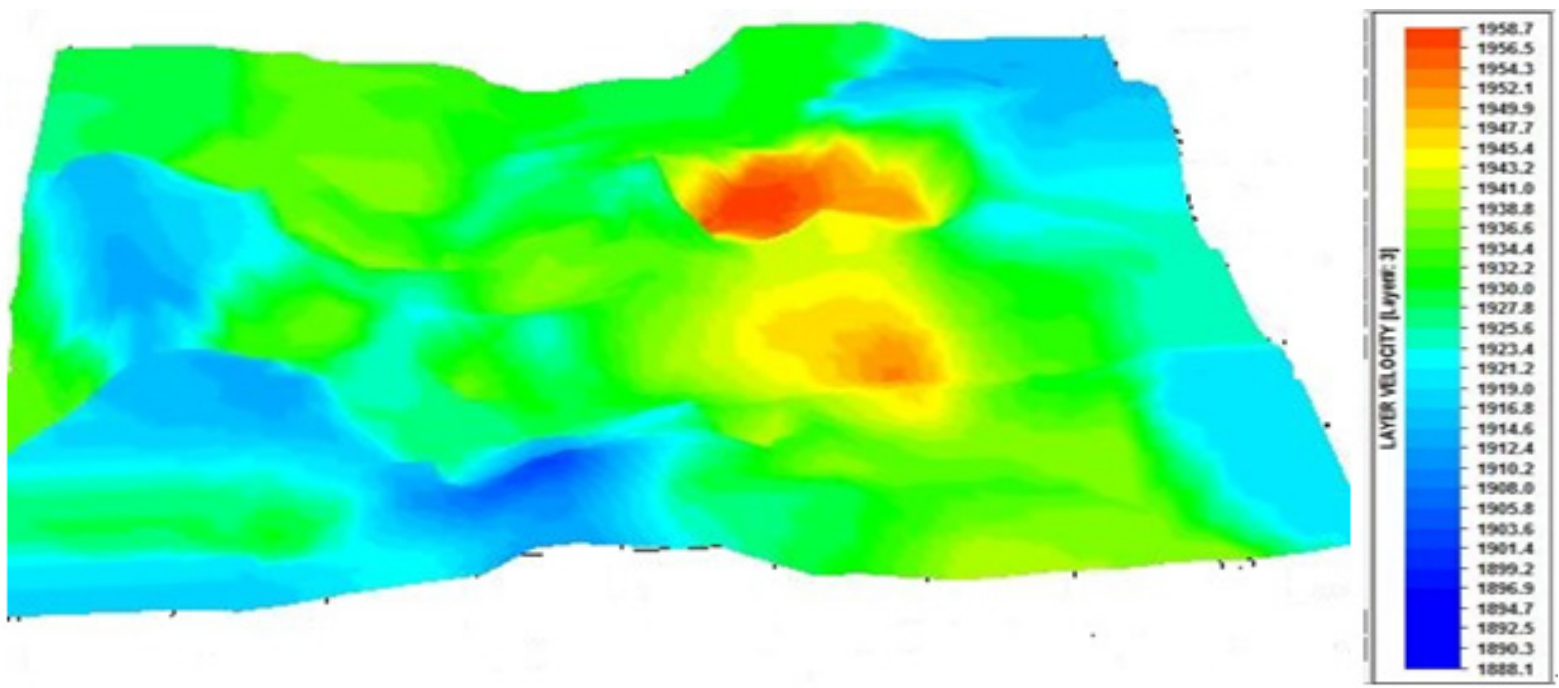

Figure 8C. Distribution of lateral velocity variation across the third consolidated layer.

Table 1. Summary of results for the weathering layer and 3 underlying layers for Cross-line and In-line

\begin{tabular}{|c|c|c|c|c|}
\hline & $\begin{array}{c}\text { Velocity (m/s) } \\
\text { (Cross-Line) }\end{array}$ & $\begin{array}{c}\text { Thickness (m) } \\
\text { (Cross-Line) }\end{array}$ & $\begin{array}{c}\text { Velocity (m/s) } \\
\text { (In-Line) }\end{array}$ & $\begin{array}{c}\text { Thickness (m) } \\
\text { (In-Line) }\end{array}$ \\
\hline Weathering layer & 450 & $3-12$ & 450 & $3-15$ \\
\hline $1^{\text {st }}$ consolidated layer & $1657-1753$ & $8-130$ & $1580-1753$ & $12-108$ \\
\hline $2^{\text {nd }}$ consolidated layer & $1737-1778$ & $66-329$ & $1744-1797$ & $50-327$ \\
\hline $3^{\text {rd }}$ consolidated layer & $1930-1959$ & $320-482$ & $1912-1959$ & $270-484$ \\
\hline
\end{tabular}

The analysis work-flow, based on refracted-wave inversion, provided a high-resolution, geologically consistent near-surface velocity model (both laterally and vertically) for a complex environment. The model is consistent in terms of its large-scale features (Figure 8) and they show the large-scale features of the subsurface clearly, making the case that the refraction inversion is robust. The velocity volume contains spatially consistent features (Figures 8A \& 8B).
The model derived from refracted waves contributes to a robust statics solution estimation as depicted in Figure 9 which could be applied to a 3D volume. This is generally possible even when other techniques (i.e., up-hole), present intrinsic limitations or cost issues (difficulties in drilling and collecting measurements). In addition to the statics solution, the near-surface velocity model can also be used for linear noise modeling and attenuation, as well as a reference model for depth imaging. 


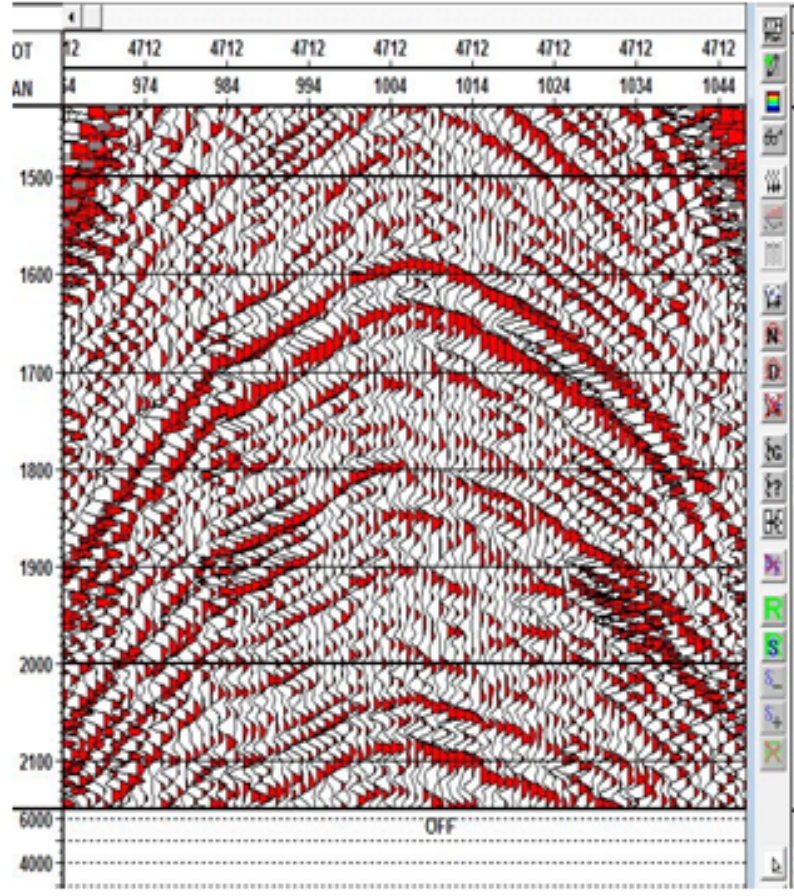

(a)

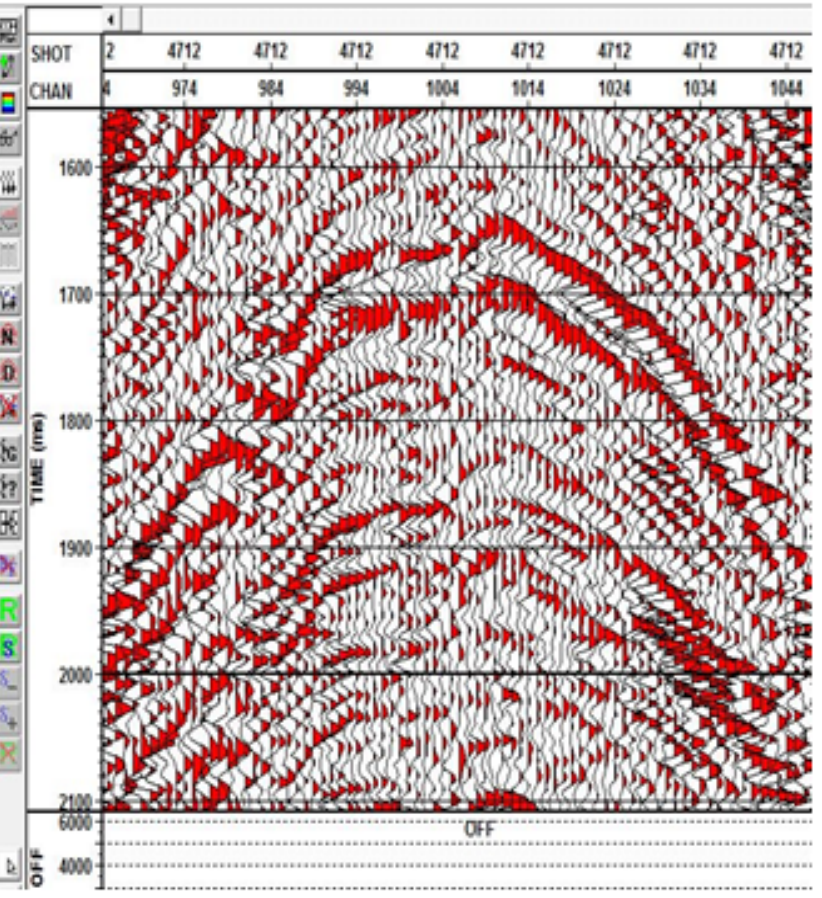

(b)

Figure 9. Preliminary Statics result based on near-surface modeling (a) after (b) before

\section{Conclusions}

The true depths of base of weathering, as well as velocities and depths of the consolidated layers for refraction points with 3-layer models were calculated. Refractions methods can provide accurate and detailed near surface velocity models. This requires proper interpretation of the refraction arrivals and an appropriate refraction inversion algorithm. The shallow velocity-depth models obtained from this technique reveal near-surface velocities and thickness structure. It can be a very good representation of the near-surface velocity and thickness variation given that the near-surface structure is layer-based without severe topography variations, and has a stable refractor, as is often the case in the Niger-delta region. The various refractors were identified and a more detailed picture of the uppermost $500 \mathrm{~m}$ was obtained.

\section{Acknowledgement}

We thank the Shell Petroleum Development Company (SPDC) Nigeria for providing the datasets used for the study and for permission to publish the research article. We equally would like to express our sincere gratitude to GEDCO Company of Canada for granting the license to use the VISTA ${ }^{\mathrm{TM}} 2 \mathrm{D} / 3 \mathrm{D}$ seismic processing software for academic use to the Applied Geophysics Research Group at the University of Port Harcourt, Nigeria.

\section{REFERENCES}

[1] Palmer, D., 1986, Refraction Seismics; Handbook of geophysical exploration, Vol. 13: Geophysical Press

[2] Cox, M., 1999. Static Corrections for Seismic Reflection Surveys: Society of Exploration Geophysicists Publ., Tulsa, Oklahoma. 1-531

[3] Obaje N.G., 2009, Geology and Mineral Resources of Nigeria. Lecture Notes in Earth Sciences,Springer

[4] Adesida A.A., Reijers T.J.A. and Nwajide, C.S., 1997, Sequence stratigraphic framework of the Niger-Delta. Paper presented at the AAPG international conference and exhibition, Vienna, Austria

[5] Odeyemi, I. B., Anifowose A. Y. B. and Asiwaju-Bello, Y.A., 1999, Remote sensing fracture characteristics of Pan African granite batholiths in the Basement Complex of parts of south western Nigeria. The Journal of Technoscience. 3: 56-60.

[6] Palmer, D., 1981, The Generalized Reciprocal Method of Seismic Refraction Interpretation. Society of Exploration Geophysicists. 1-104

[7] Khan, K.A., 1994, An intelligent and efficient approach to picking first breaks. 56th Mtg., Eur. Assn. Expl. Geophys, Paper P155

[8] Bridle, R., and Aramco, S., 2009. Delay-Time Refraction Methods Applied to a 3D Seismic Block. The Leading Edge, 28(2): 228-237

[9] Hao, J., Yang, R. J., and Wu, J., 2011. Processing of Static Correction Problems of Seismic Data in the Complex Surface. 
[10] Pelton, J.R., 2005, Near-surface seismology: Surface-basedmethods in Near-Surface Geophysics, Butler, D. (ed.),Society of Exploration Geophysics, Tulsa, OK 219-263.

[11] Steeples, D. W., Miller, R. D., and Black, R. A., 1990, Static corrections fromshallow reflection surveys: Geophysics, 55 , $769-775$

[12] Zhu, X. S., Gao, R., and Li, Q. S., 2014. Static corrections methods in the processing of deep reflection seismic data. Journal of Earth Science, 25(2):299-308 